\title{
Recent Trends in Behavioral Environmental Economics
}

\author{
Martin Kesternich $^{1}$. Christiane Reif ${ }^{1}$. \\ Dirk Rübbelke ${ }^{2}$
}

Published online: 1 June 2017

C) Springer Science+Business Media Dordrecht 2017

\section{Introduction}

The first fundamental theorem of standard welfare economics states that any equilibrium achieved by a competitive market leads to a Pareto efficient allocation of resources. Yet, due to market failures, inefficiencies regularly occur. As Cornes (2016: p 339) points out a "decentralized market equilibrium is likely to be inefficient as a consequence of various externalities, or spillovers." Individual incentives are often at odds with collective group interest being described as the "impossibility of decentralized spontaneous solutions", which are optimal (Samuelson 1954: p. 388). The domain of environmental economics looks back on a long history of developing solutions to these market failures (Shogren and Taylor 2008). Externalities and environmental public goods provide typical examples for market failures in environmental economics (e.g. Fullerton and Stavins 1998). Instruments established through government intervention may help to overcome such social dilemma situations and to prevent an inefficient allocation of resources. However, in many situations formal top-down regulation is far from being easy to implement or may even be impossible. In the case of global public goods no central international authority exists being able to enforce such interventions among sovereign countries (see e.g. Barrett 1994; Kaul et al. 1999; Altemeyer-Bartscher et al. 2010; Löschel and Rübbelke 2014; Kaul 2017). This in turn means that voluntary action becomes crucial even though only second best solutions might be reached.

Researchers and policy makers are interested in how to stimulate such voluntary action through appropriate incentives. From an economic point of view, such behavior involves

$凶$ Dirk Rübbelke

Dirk.Ruebbelke@vwl.tu-freiberg.de

Martin Kesternich

kesternich@zew.de

Christiane Reif

reif@zew.de

1 Centre for European Economic Research (ZEW), L7,1, 68161 Mannheim, Germany

2 Technische Universität Bergakademie Freiberg, Schloßplatz 1, 09599 Freiberg, Germany 
acting against one's strict self-interest in many decision situations. The canonical economic model of behavior is based on the idea of 'homo oeconomicus'. As, for instance, formulated by Kirchgäßner (2008: 9), the homo oeconomicus is based on the two central assumptions of fully rational and purely self-interested behavior. The critique concerning the idea of homo oeconomicus exhibits various facets and is therefore rather divergent.

As an example, the orthodox and classical rationality assumption is largely assessed to be violated in many situations (Doucouliagos 1994). Yet, as Doucouliagos (1994: 879) points out, bounded rationality "[...] does not alter the essentially rational nature of Homo Economicus; it merely redefines the boundaries of rationality." Understanding these boundaries of rational behavior is key to design applicable instruments in the field of environmental economics. At the same time, economic experiments provide evidence of individuals acting not entirely selfish but caring about fairness in many economic settings. These observations have inspired the theoretical literature to include fairness motives into the utility framework (see e.g. Meier 2006 for an overview).

The behavioral economics literature challenges the concept(s) of homo oeconomics and its two main pillars of characterization-self-interest and rationality. Inter alia, Fehr and Gächter (1998) paired the homo oeconomicus with the so-called 'homo reciprocans', a person whose behavior is influenced by the idea of reciprocity. Besides the research field on self-interest, there is also a broad field of research on the rationality assumption. Camerer and Fehr (2006) point out that the (unbounded) rationality assumption builds on two aspects, namely correct beliefs - the judgement of an event or others' behavior — and decision-making according to own preferences based on these beliefs. In turn, the limits in humans' cognitive abilities lead to deviations in both components (Mullainathan and Thaler 2000). Simon (1955) denoted these cognitive constraints as bounded rationality. Camerer (1999) summarizes how the findings of experimental work by psychologists and economists have contributed to behavioral principles and links them to the corresponding economic standard theory. In this regard, he refers to four concepts: expected utility and prospect theory, equilibrium and learning, discounting utility and hyperbolic discounting, payoff maximization and social utility. These research areas are taken up by later survey articles on the topics of behavioral economics (see e.g. Mullainathan and Thaler 2000; Venkatachalam 2008; Pesendorfer 2006; Shogren et al. 2010; Gsottbauer and van den Bergh 2011) and are still subject of theoretical and empirical research aiming either at providing general applicable descriptions of human behavior or at explaining individuals' actions in specific contexts. As Carlsson and Johansson-Stenman (2012) point out the main policy concerns in the environmental context are about externalities and not about bounded rationality or willpower. However, Croson and Treich (2014) stress that the complexity of environmental concerns, especially the long time perspective and the global dimension, might be the breeding ground for bounded rational behavior. The importance of behavioral economics for environmental economics is taken up by survey articles with different focus areas (see e.g. Brekke and Johansson-Stenman 2008; Shogren and Taylor 2008; Venkatachalam 2008; Shogren et al. 2010; Carlsson and Johansson-Stenman 2012; Croson and Treich 2014).

In these survey articles the authors discuss how far the standard model is applicable. Brekke and Johansson-Stenman (2008) emphasize that especially the findings concerning risk attitudes and preferences over time are particularly relevant in the context of climate change. Venkatachalam (2008) focuses on environmental policy and argues that policy failures are partly driven by neglecting behavioral aspects when applying policy interventions. Shogren and Taylor (2008) explain that standard theory cannot adequately predict actual behavior in the environmental context as soon as markets fail and people do not behave as homines oeconomici. This is because rationality in economics is a social construct defined by market- 
like arbitrage (see e.g. Arrow 1986). However, Shogren et al. (2010) argue that the standard theory can still provide as useful upper benchmark acting as comparison for revealed behavior. Brekke and Johansson-Stenman (2008) as well as Carlsson and Johansson-Stenman (2012) stress the social context as an additional factor-besides individuals' non material motivation and their unbounded rationality - which differentiates behavioral economics from standard theory. Croson and Treich (2014) highlight that alternative policy instruments (e.g. nudges) make use of individuals' deviations from the homo oeconomicus and postulate that for future policy measures the combination of economic incentives as well as behavioral aspects should be taken into account.

The discussions of all these authors have in common that they refer to "human behavior', which differentiates empirical observations from standard theory. Acknowledging that standard theory in many situations fails to predict actual human behavior adequately raises the demand for extensions of the standard model (see e.g. Chetty 2015). Thaler (2016) puts it slightly different when distinguishing models by their objective: (i) theories explaining optimal behavior being related to the standard theory, and (ii) concepts explaining actual behavior. The second category incorporates what we might have in mind when talking about behavioral economics or the extensions of the standard theory.

Starting from the several survey articles on behavioral economics and especially the recent summary on the development of behavioral economics by Thaler (2016), one can observe that the field of behavioral economics categorizes, broadens and deepens at the same time. Rabin (2006) points out that a review of experimental work cannot lead to a consensus of general validity because the diversity of research-in horizontal (type of preferences) and vertical (context) direction-limits the universal validity. Nevertheless, pave grounding work by Simon in the 1950s (see Simon 1955) or by Kahneman and Tversky in the 1970s (see Kahneman and Tversky 1979) show common patterns of behavior-or as Ariely (2010) put it in his book title: 'predictably irrational' behavior. Based on their observed structure of actual behavior, a huge field of research popped up trying to explain these patterns or aiming to observe other commonly applicable behavioral structures.

The more recently taken vertical direction in behavioral economics is research were context is explicitly considered and taken into account when designing appropriate instruments. Levitt and List $(2007 \mathrm{a}, \mathrm{b})$ emphasize that even a qualitative understanding of human behavior is of interest. This more detailed view on how human's behavior in their natural environment is especially addressed by field or framed experiments, analyzing specific subject pools or research of a specific political context.

This horizontal and vertical broadening of the behavioral economics research further breaks down Thaler's (2016) two-part distinction of theories. The research on actual human behavior could be further distinguished, on the one hand, into research where human behavior deviates from the homo oeconomicus but is somehow predictable by general patterns of behavior. On the other hand, theories which do not describe a common phenomenon, but explain context dependent behavior. For the implementation of policy instruments, knowledge of all these research directions is needed to get structures as well as details right. As such, future policy instruments should bring together standard theory, on what would be the optimal behavior we might be aiming for at the political level, and the very practical perspective on how to reach this goal by incorporating knowledge about actual behavior, the very specific context, and the practical details of implementation. This is similar to what Croson and Treich (2014) claim for future policy instruments.

In March 2015, we organized a workshop on "Behavioral Environmental Economics" at the Centre for European Economic Research (ZEW) in Mannheim/Germany in order to present and discuss ongoing and future developments in behavioral environmental economic 
research. The contributions to this Special Issue were among the papers presented at the workshop. In the following two sections, we discuss the individual papers of this special issue. Afterwards, we provide a short outlook on future perspectives of the research field.

\section{Can Non-monetary Interventions Work in the Long Run, Create Spillovers to Related Decision-Making Situations and Interplay with Monetary Incentives?}

In recent years, non-monetary interventions grounded at the intersection of psychology and behavioral economics have broadened the economic toolkit to stimulate environmental protection and resource conservation. These small scale behavioral "nudges" typically include commitment devices, information provision, social norms, goal setting, or default options (Allcott and Mullainathan 2010). A growing number of empirical applications in a variety of environmental economic settings (e.g. water use, electricity consumption, recycling) underline their (short-term) effectiveness.

In this field of non-monetary interventions, long-term and spillover effects and the interplay with monetary incentives are gaining importance in current research. In the environmental context, the long-term perspective of interventions like public information campaigns is of particular importance: Do consumers fall back into their previous behavioral patterns or do they maintain their behavior at a re-optimized level? Allcott and Rogers (2014) provide evidence on the impact of social feedback on electricity consumption in households and report that immediate conservation efforts vanish a few months after treatment exposure if the treatment is not repeated. Distinguishing between continued reporting for two more years and discontinued reporting after two years provides evidence that consumers do not fully adapt even after two years. The response to the intervention is 50 to $60 \%$ stronger if the treatment is continued instead of interrupted. With their investigations on the long-term impact of social information on residential water consumption, Ferraro et al. (2011) find that only messages which contain social feedback have long lasting impacts two years after the message has been sent. Long-term impacts of monetary incentives (Kesternich et al. 2016) and non-monetary behavioral interventions (Kesternich et al. 2016b) have also recently been addressed in voluntary $\mathrm{CO}_{2}$ offsetting programs. Kesternich et al. (2016b) examine repeated voluntary contributions to a carbon offsetting program during the online purchase of longdistance bus tickets. In one condition, travelers were forced to actively choose whether to offset their carbon emissions or not. This active choice increased the offsetting of first time bookings by almost $50 \%$ and remained effective for repeated booking decisions. However, at the same time, a significant share of returning customers constantly attempts to avoid the decision. This result is consistent with observations in the field of charitable giving where subjects take efforts to avoid meeting a solicitor asking for donations (Andreoni et al. forthcoming, DellaVigna et al. 2012). In the similar domain, Gallier et al. (2017) study spillover effects of economic incentives in repeated donations decisions.

Besides the applicability in other frameworks, an important dimension of non-monetary incentives becomes relevant if their long-term impacts include potential spillover effects: Can specific social information within one area of behavior trigger similar reactions in related but different fields of consumption? Carlsson et al. (2016) explore the impact of a social information campaign targeting water conservation in households on the use of residential electricity. While the social information campaign within the monthly bills reduces water use both for households with inefficient and efficient water consumption in the pre-intervention 
period, positive spillover effects can only be observed for the latter group: After 11 months, this group on average consumes $9 \%$ less electricity than the control group.

As already Croson and Treich (2014) pointed out, the interplay of behavioral and economic incentives are of interest for future research. Also in the environmental context, ethical concerns and financial savings come into play: What is the role of intrinsic incentives and extrinsic incentives in social information settings like household electricity savings? Pellerano et al. (2016) report field experimental evidence from Quito/Ecuador which suggests that adding price salience to a social comparison letter does not add additional impacts to the saving rates but in contrast, may even backfire by diluting the extent to which voluntary contributions signal pro-social behavior to oneself. In a related setting, Uehleke and Sturm (2016) assess the demand for voluntary climate change mitigation in a collective action decision framework both in a hypothetical and a real money incentive setting. While a collective action appears to substantially increase the demand for climate protection in the hypothetical scenario, this finding does not spill over to a setting where subjects face real monetary incentives. Lohse et al. (2016) use a more abstract framed field experimental setting to highlight the impact of a decision environment being principally conducive to different cognitive styles (such as intuition or reflection) on voluntary climate mitigation efforts. Analyzing the difference in response times between subjects who purchase and offset allowances from the EU-ETS and those who do not, they find that intuitive (fast) decisions are associated with a choice to refrain from contributing. At the same time, contributions are more likely when a decision follows reflection. Average response time for contributors is $40 \%$ higher than for non-contributors. This relationship, which holds both between and within subjects, indicates that deliberation and not intuition is the cognitive style which supports individual mitigation efforts. Furthermore, triggering an intrinsic moral motivation could also support an economic commitment. Jaquement et al. (2016) experimentally investigate whether an oath can create a real economic commitment to reduce the hypothetical bias in a voting referendum. In their experiment, groups of five players agree on whether to adopt a dolphin via WWF through majority voting in five successive referenda. Their findings reveal that an oath effectively reduces the observed hypothetical bias, especially for those subjects with consistent voting behavior across the different referenda.

This research represents the vertically extension of behavioral economics by incorporating the context and furthermore consider the long-term and spillover effects as well as the interplay with monetary incentives. Further research in this direction is needed to better understand what situations lead subjects to behave similarly and how interventions might spill over, backfire in different areas or interact with monetary incentives. This is of special interest for enabling environmental economics to better predict whether environmental targets are reachable with a specific intervention.

\section{How Can Informal Institutions Address Transboundary Social Dilemma Situations?}

A further strand of the behavioral environmental literature has focused on the institutional design for providing international public goods. Since formal institutions are rarely able to enforce internationally the collectively desirable outcomes, informal institutions, such as social norms, can become an important tool to stimulate norm changes and address transboundary social dilemma situations (Nyborg et al. 2016). Nyborg et al. (2016) describes social norms as shared rules of conduct within a group which also form fairness perceptions in two directions: On the one hand, fairness itself seems to matter for some individuals. On the 
other hand, the judgement whether others consider oneself's behavior as fair is also taken into account in an individual's decision making (Andreoni and Bernheim 2009). Social norms and fairness considerations could be drawn upon to promote voluntary public goods provision. As a prominent example, notions of equity and fairness perceptions in international climate negotiations have been intensively studied in recent years; e.g. Pittel and Rübbelke (2013) investigate approaches to raise fairness perception in international environmental negotiations and illustrate how this might affect the outcome of negotiations. While the empirical evidence from agents involved in international climate policy rather suggest that equity arguments are mainly used in a self-serving manner (Lange et al. 2007, 2010)—even though the fairness bias appears to be somewhat lower if weights for different burden sharing rules can be negotiated (Kesternich et al. 2014) — there is mixed evidence from surveys among citizens (Carlsson et al. 2012, 2013; Schleich et al. 2016). Lange and Schwirplies (2017) provide a new perspective on the strategic use of equity arguments in international climate policy. By enriching a theoretical model of strategic delegation with preferences for fairness and environmental concerns, they show that the strategic use of equity arguments crucially depends on the extent to which environmental preferences can strategically misrepresented. While conflicts on equity issues arise when environmental preferences are fixed as countries may send representatives who perceive a smaller burden share as fair, representatives from different countries may be expected to have similar equity views if they can strategically bias the environmental preference downward. ${ }^{1}$ These potential strategic misrepresentations of equity and environmental preferences in international climate negotiations are then empirically explored by comparing survey data on preferences of citizens from Germany, China, and the U.S. with perceived views on the negotiation position of the respective countries.

Are groups of heterogeneous agents able to reach an agreement on how to share the costs of providing a public good? Gallier et al. (2016) experimentally investigate the performance of different burden sharing rules in different voting schemes. Despite the fact that preferences for different allocation schemes differ among agents, most groups agree upon a common scheme and consequently avoid an uncoordinated action. While average contribution levels increase if an agreement is reached, cooperation collapses and efficiency levels decrease compared to a voluntary contribution mechanism (VCM) being exogenously imposed. Most notably, for all average agents who face a voting decision, payoffs are higher compared to an exogenously implemented VCM. But how to enforce social norms? Sanctioning schemes gained attraction in research as they foster social norms and therefore cooperation in public good provision (see also Fehr and Fischbacher 2004). Reif et al. (2017) experimentally analyze whether individuals are willing to implement a punishment and reward scheme at their own expense. The experiment is based on the theory by Buchholz et al. (2014) which introduces an endogenously determined norm-enforcement mechanism. Subjects are apparently willing to contribute their funds to establish such a norm enforcement mechanism. The mechanism promotes cooperation and higher public good contributions are observed with a stricter mechanism. However, the over-contribution in the first rounds to establish the mechanism decreases over time. But is it worth to invest in such norm-establishment when sanctioning is not possible, in situations without neither a government nor an international agreement, and it is uncertain whether other follow?

This leads to the question if environmental leadership would even lead to a better environmental performance. Buchholz and Sandler (2016) study, which role of leadership, which consists in unilateral increases of a country's contribution to the global public good 'climate

1 These findings extent previous research by Buchholz et al. (2005) which focuses on strategic delegation but abstracts from equity arguments. 
protection', may exert as a motivational push for mitigation activities of other countries in a theoretical framework with other-regarding preferences. They provide insights into the formation of reciprocal beliefs and trust building that help to entail a positively sloped reaction function and thus makes leadership successful. This finding particularly holds if the leaders' contribution positively affects the followers' beliefs or if the follower possesses non-egoistic or other-regarding preferences. The institutional design for providing international public goods depends also on risk attitudes as they might interact with equity concerns. The steady progress in climate change could result in catastrophic events. What are or what should be society's attitudes towards low-probability, high-impact events? Rheinberger and Treich (2016) provide a review of different methods from decision sciences, psychology and behavioral economics which aim at exploring individuals' attitudes towards social risks. Their findings suggest, perhaps surprisingly, that individuals tend to be catastrophe accepting and not catastrophe averse. This might be explained by inequity aversion since maximal ex-post equity is attained in the extreme case when either nobody or everybody is a victim.

The articles in this special issue reflect the huge variety of research topics in the field of behavioral economics. The last decades of research dedicated to behavioral economics have scontributed to shape and push our knowledge about actual human behavior forward, but still further theoretical advancements based on solid experimental and empirical investigations are needed.

Acknowledgements We thank the Editor Ian Bateman who made this Special Issue possible. His thorough and helpful comments and advice supported us in the process of publishing. We thank Wolfgang Buchholz, Jason Shogren and Sebastian Otte for their helpful comments on this introduction for the Special Issue. We are grateful to all authors that participated in the workshop "Behavioral Environmental Economics" and contributed to this Special Issue.

\section{Compliance with ethical standards}

Conflict of interest The authors are not aware of any affiliations, memberships, funding, or financial holdings that might be perceived as affecting the objectivity of this review. We thank the Fritz Thyssen Foundation for financial support of the workshop "Behavioral Environmental Economics" held in 2015. The special issue represents the collection of papers presented at the workshop.

\section{References}

Allcott H, Mullainathan S (2010) Behavioral science and energy policy. Science 327:1204-1205

Allcott H, Rogers T (2014) The short-run and long-run effects of behavioral interventions: experimental evidence from energy conservation. Am Econ Rev 104(10):3003-3037

Altemeyer-Bartscher M, Rübbelke D, Sheshinski E (2010) Environmental protection and the private provision of international public goods. Economica 77(308):775-784

Andreoni J, Bernheim BD (2009) Social image and the 50-50 norm: a theoretical and experimental analysis of audience effects. Econometrica 77(5):1607-1636

Andreoni J, Rao JM, Trachtman H (forthcoming.) Avoiding the ask?: a field experiment on altruism, empathy, and charitable giving. J Polit Econ

Ariely D (2010) Predictably irrational, revised: the hidden forces that shape our decisions. Harper Collins Publishers, New York

Arrow KJ (1986) Rationality of self and others in an economic system. J Bus 59(4):385-399

Barrett S (1994) Self enforcing international environmental agreements. Oxford Econ Pap 46:878-894

Brekke KA, Johansson-Stenman O (2008) The behavioural economics of climate change. Oxford Rev Econ Policy 24(2):280-297

Buchholz W, Sandler T (2016) Successful leadership in global public good provision: incorporating behavioural approaches. Environ Resour Econ. doi:10.1007/s10640-016-9997-2 
Buchholz W, Haupt A, Peters W (2005) International environmental agreements and strategic voting. Scand J Econ 107:175-195

Buchholz W, Falkinger J, Rübbelke D (2014) Non-governmental public norm enforcement in large societies as a two-stage game of voluntary public good provision. J Public Econ Theory 16(6):899-916

Camerer C (1999) Behavioral economics: reunifying psychology and economics. Proc Natl Acad Sci 96(19):10575-10577

Camerer C, Fehr E (2006) When does "economic man” dominate social behavior? Science 311(5757):47-52

Carlsson F, Johansson-Stenman O (2012) Behavioral economics and environmental policy. Annu Rev Resour Econ 4(1):75-99

Carlsson F, Kataria M, Krupnick A, Lampi E, Löfgren Å, Qin P, Chung S, Sterner T (2012) Paying for mitigation: a multiple country study. Land Economics 88:326-340

Carlsson F, Kataria M, Krupnick A, Lampi E, Löfgren Å, Qin P, Sterner T, Chung S (2013) A fair shareburden-sharing preferences in the United States and China. Resour Energy Econ 35:1-17

Carlsson F, Torres MMJ, Villegas CI (2016) Spillover Effects from a Social Information Campaign. EfD DP: $16-06$

Chetty R (2015) Behavioral economics and public policy: a pragmatic perspective. Am Econ Rev 105(5):1-33

Cornes R (2016) Aggregative environmental games. Environ Resource Econ 63(2):339-365

Croson R, Treich N (2014) Behavioral environmental economics: promises and challenges. Environ Resource Econ 58:335-351

DellaVigna S, List JA, Malmendier U (2012) Testing for altruism and social pressure in charitable giving. Q J Econ 127:1-56

Doucouliagos C (1994) A note on the evolution of homo economicus. J Econ Issues 28(3):877-883

Fehr E, Fischbacher U (2004) Social norms and human cooperation. Trends Cogn Sci 8(4):185-190

Fehr E, Gächter S (1998) Reciprocity and economics: the economic implications of homo reciprocans. Eur Econ Rev 42:845-859

Ferraro PJ, Miranda JJ, Price MK (2011) The persistence of treatment effects with norm-based policy instruments: evidence form a randomized environmental policy instrument. Am Econ Rev 101:318-322

Fullerton D, Stavins R (1998) How economists see the environment. Nature 395:433-434

Gallier C, Kesternich M, Sturm B (2016) Voting for burden sharing rules in public goods games. Environ Resour Econ. doi:10.1007/s10640-016-0022-6

Gallier C, Reif C, Römer D (2017) Repeated pro-social behavior in the presence of economic interventions. J Behav Exp Econ 69:18-28

Gsottbauer E, van den Bergh JCJM (2011) Environmental policy theory given bounded rationality and otherregarding preferences. Eviron Resour Econ 49(2):263-304

Jaquement N, James A, Luchini S, Shogren JF (2016) Referenda under Oath. Environ Resour Econ. doi:10. 1007/s10640-016-0023-5

Kahneman D, Tversky A (1979) Prospect theory: an analysis of decision under risk. Econometrica 47(2):263292

Kaul I (2017) Putting climate finance into context: a global public goods perspective. In: Markandya A, Galarraga I, Rübbelke D (eds) Climate finance-theory and practice. World Scientific Publishing, Singapore, pp 129-156

Kaul I, Grunberg I, Stern M (1999) Global public goods: international cooperation in the 21st century. Oxford University Press, Oxford

Kesternich M, Löschel A, Ziegler A (2014) Negotiating weights for burden sharing rules among heterogeneous parties: empirical evidence from a survey among delegates in international climate negotiations. ZEW discussion Paper series no 14-031, Mannheim

Kesternich M, Löschel A, Römer D (2016a) The long-term impact of matching and rebate subsidies when public goods are impure: field experimental evidence from the carbon offsetting market. J Public Econ 137:70-78

Kesternich M, Römer D, Flues F (2016b) The power of active choice: field experimental evidence on repeated contribution decisions to a carbon offsetting program. ZEW Discussion Paper no 16-091

Kirchgäßner G (2008) Homo oeconomicus: the economic model of behaviour and its applications in economics and other social sciences. Springer, New York

Lange A, Schwirplies C (2017) (Un)fair delegation: exploring the strategic use of equity rules in international climate negotiations. Environ Resource Econ. doi:10.1007/s10640-017-0140-9

Lange A, Vogt C, Ziegler A (2007) On the importance of equity in international climate policy: an empirical analysis. Energy Econ 29:545-562

Lange A, Löschel A, Vogt C, Ziegler A (2010) On the self-interested use of equity in international climate negotiations. Eur Econ Rev 54(3):359-375 
Levitt SD, List JA (2007a) Viewpoint: on the generalizability of lab behaviour to the field. Can J Econ 40(2):347-370

Levitt SD, List JA (2007b) What do laboratory experiments measuring social preferences reveal about the real world? J Econ Perspect 21(2):153-174

Lohse J, Goeschl T, Diederich JH (2016) Giving is a question of time: response times and contributions to an environmental public good. Environ Resour Econ. doi:10.1007/s10640-016-0029-z

Löschel A, Rübbelke D (2014) On the voluntary provision of international public goods. Economica 81(322):195-204

Meier S (2006) A survey of economic theories and field evidence on pro-social behavior. FRB of Boston working paper no. 06-6, Federal Reserve of Bank of Boston

Mullainathan S, Thaler RH (2000) Behavioral economics. NBER working paper series (7948), Cambridge, MA

Nyborg K, Anderies JM, Dannenberg A, Lindahl T, Schill C, Schlüter M, Adger WN, Arrow KJ, Barrett S, Carpenter S, Chapin FS III, Crépin A-S, Levin SA, Madsen OJ, Polasky S, Scheffer M, Walker B, Weber EU, Wilen J, Xepapadeas A, de Zeeuw A (2016) Social norms as solutions. Science 654:42-43

Pellerano JA, Price MK, Puller SL, Sánchez GE (2016) Do extrinsic incentives undermine social norms? evidence from a field experiment in energy conservation. Environ Resour Econ. doi:10.1007/s10640016-0094-3

Pesendorfer W (2006) Behavioral economics comes of age: a review essay on advances in behavioral economics. J Econ Lit 44(3):712-721

Pittel K, Rübbelke D (2013) International climate finance and its influence on fairness and policy. World Econ 36(4):419-436

Rabin M (2006) The experimental study of social preferences. Soc Res 73(2):405-429

Reif C, Rübbelke D, Löschel A (2017) Improving voluntary public good provision through a non-governmental, Endogenous Matching Mechanism experimental evidence. Environ Resour Econ. doi:10.1007/s10640017-0126-7

Rheinberger CM, Treich N (2016) Attitudes toward catastrophe. Environ Resour Econ. doi:10.1007/s10640016-0033-3

Samuelson PA (1954) The pure theory of public expenditure. Rev Econ Stat 36:387-389

Schleich J, Dütschke E, Schwirplies C, Ziegler A (2016) Citizens' perceptions of justice in international climate policy: an empirical analysis. Clim Policy 16:50-67

Shogren JF, Taylor LO (2008) On behavioral-environmental economics. Rev Environ Econ Policy 2(1):26-44

Shogren JF, Parkhurst GM, Banerjee P (2010) Two cheers and a qualm for behavioral environmental economics. Eviron Resour Econ 46(2):235-247

Simon H (1955) A behavioral model of rational choice. Q J Econ 69(1):99-118

Thaler RH (2016) Behavioral economics: past, present, and future. Am Econ Rev 106(7):1577-1600

Uehleke R, Sturm B (2016) The influence of collective action on the demand for voluntary climate change mitigation in hypothetical and real situations. Environ Resour Econ. doi:10.1007/s10640-016-0028-0

Venkatachalam L (2008) Behavioral economics for environmental policy. Ecol Econ 67(4):640-645 